\title{
Issues of recruitment and maintaining high response rates in a longitudinal study of older hospital patients in England-pathways through care study
}

Barbara A Gregson, Monica Smith, Jan Lecouturier, Nikki Rousseau, Helen Rodgers, John Bond

\begin{abstract}
Study objectives-To describe and discuss the methods used to recruit and maintain an unbiased sample of older discharged hospital patients in a study of the process and outcomes of hospital care.

Design-Prospective longitudinal interview study of consecutive patients admitted to hospital over a 12 month period and followed up for six months. Interviews took place in hospital five days after admission, at home 10 days after discharge, and six months after admission.

Setting-Six hospital locations: three in the north of England and three in the south.
\end{abstract}

Participants-People aged 65 and over admitted to hospital with a new stroke or fractured neck of femur, their significant other, and nursing staff caring for them. Main results-Of 3105 patients referred to the study, 2111 were eligible and 1671 (79\%) were recruited. Recruited stroke patients were younger than those not recruited and rates differed between locations for both stroke and fractured neck of femur. By six months after admission $25 \%$ had died. Outcome data were obtained for $85 \%$ of the surviving patients. Patients who died were older and frailer before admission. Among survivors, outcome data for stroke patients were less likely to be obtained for men, those more able initially, and those who were married. Response rates to each interview differed according to respondent types. Interviews were more likely to be obtained with significant others than patients. Patients who were not able to be interviewed were older and frailer; significant others were less likely to be interviewed if the patients were younger and more able.

Conclusions-High response rates can be achieved with very frail older people if strategies are adopted to maintain their interest and if self reported data are supplemented by interviewing significant others.

$(尹$ Epidemiol Community Health 1997;51:541-548)

Prospective longitudinal studies are an important method of examining health policy issues.
The confidence with which findings can be accepted and generalised on depends on how representative the initial and final samples are of the target population. Poor response rates at baseline are a potential source of bias, since non-respondents are likely to differ from respondents in important characteristics. ${ }^{1}$ The potential magnitude of selection bias rapidly increases with decreasing response rates and measures to reduce the number of nonrespondents are essential. ${ }^{2}$ Attrition in longitudinal studies may introduce further biases, particularly if loss to follow up is differential with regard to important subject characteristics. Even where a sample is initially representative there is no assurance that it will remain so over time. ${ }^{3}{ }^{4}$ There are two main reasons for attrition and it is important to distinguish between them: one is differential survival and the other is selective drop out.

POOR RESPONSE

Poor response in health surveys is associated with advancing age, low educational level, semi-skilled and unskilled manual occupations, and poorer health status, ${ }^{5-11}$ although examples of the opposite can be found. ${ }^{10-12}$ In older populations the prevalence of cognitive impairment increases and this affects a respondents' ability to complete an interview. Poor response is aggravated when the subject of study is acutely ill, for instance when they are patients early in a hospital stay. Reasons for refusal in this situation include: not feeling well, a general suspicion of studies, concern about signing consent forms, anxiety about being in hospital, and protective relatives. ${ }^{8}$ Patients may be confused and worried because of the stress of hospitalisation and the anxiety of wondering what will happen after discharge. ${ }^{13}$ Obtaining informed consent is a problem when subjects find it difficult to understand the nature and purpose of the research and to read and understand the language of consent forms. In addition, the ability to complete an interview may be affected by vision and hearing impairments. ${ }^{9}$

\section{ATTRITION}

In longitudinal studies differential survival is associated with poorer health status and increasing age. Selective drop out, due to refusal and other causes, is also associated with 
poorer physical health, higher rates of intellectual impairment, and lower socioeconomic status. ${ }^{14}{ }^{15}$ In studies of older people, attrition is critical because mortality, morbidity, and moving home are more likely to occur. ${ }^{14}{ }^{16}$ Initial non-response and attrition are critical issues in studies of older people recruited in hospital and followed up after discharge. This paper describes the approach used to minimise initial refusal and subsequent drop out and looks at the potential biases introduced by these two factors in a prospective longitudinal study of older people admitted to hospital for an acute episode and followed up for six months. The study, "pathways through care", was commissioned by the Department of Health to examine the continuity of care between hospital and community, particularly from the perspectives of patients and their significant others. Although the discharge process was the focus of the study it was necessary to prospectively recruit patients at admission to hospital in order to observe the preparation for discharge and to ensure that the study population was representative of older people discharged from hospital.

\section{Methods}

DESIGN

A prospective longitudinal study was conducted in six non-teaching hospitals selected on theoretical grounds to illustrate different models of medical and orthopaedic care; to have sufficient admissions of study subjects over a 12 month period; and to serve populations with different socioeconomic characteristics.

\section{STUDY LOCATIONS}

Three locations were in the north of England. Two were industrial city areas with an above average proportion of local authority housing and unskilled workers and high levels of unemployment. The third northern location com-

Table 1 Interview time points

\begin{tabular}{lllll}
\hline Interview type (time point) & $\begin{array}{l}\text { Admission (5d } \\
\text { after admission) }\end{array}$ & $\begin{array}{l}\text { Discharge (d } \\
\text { of discharge) }\end{array}$ & $\begin{array}{l}\text { Discharge (10d } \\
\text { after discharge) }\end{array}$ & $\begin{array}{l}\text { Outcome (6 mth } \\
\text { after admission) }\end{array}$ \\
\hline $\begin{array}{l}\text { Respondent } \\
\text { Patient }\end{array}$ & & & \\
$\begin{array}{l}\text { Significant other } \\
\text { Staff (hospital nurse) }\end{array}$ & - & & & \\
\hline
\end{tabular}

Table 2 Recruitment to the study

\begin{tabular}{lccc}
\hline & & Fractured neck of & \\
& Stroke & All \\
& No (\%) & No (\%) & No (\%) \\
\hline Referred to study & 1645 & 1460 & 3105 \\
Not approached: & $46(3)$ & $39(3)$ & $85(3)$ \\
$\quad$ Already in study & $11(1)$ & $10(1)$ & \\
Referred during halt in recruitment & $35(2)$ & $29(2)$ & \\
Not eligible: & $708(43)$ & $201(13)$ & $909(29)$ \\
Died before admission interview & $222(14)$ & $57(4)$ & \\
Discharged before admission interview & $55(3)$ & $54(4)$ & \\
Too ill to be approached & $67(4)$ & $19(1)$ & \\
Too young & $4(0)$ & $5(0)$ & \\
Final diagnosis not stroke or fracture & $360(22)$ & $66(4)$ & \\
Eligible & $891(54)$ & $1220(84)$ & $2111(68)$ \\
Not recruited: & $205(23)$ & $235(19)$ & $440(21)$ \\
Refused & $120(13)$ & $143(12)$ & \\
Consent not obtained & $85(10)$ & $92(7)$ & $1671(79)$ \\
Recruited & $686(77)$ & $985(81)$ & 1670 \\
\hline
\end{tabular}

KEY POINTS

- Prospectively collected inpatient information makes a significant contribution to our understanding of the hospital discharge process.

- Prospective study of the discharge process requires large resources in order to approach and recruit a sample that is sufficiently large and representative.

- Frail older people are willing respondents in longitudinal surveys provided appropriate strategies sensitive to their situation are adopted.

- In order not to disenfranchise the frailest subjects it is necessary to collect data from significant others as well.

prised a city with an average demographic structure surrounded by a very rural area with an older population. The three locations from the south of England included two south coast resort and retirement areas featuring a much older population and a low proportion of local authority housing. The third southern location was a growth area with a younger population and low unemployment.

\section{STUDY POPULATION AND RECRUITMENT}

Patients aged 65 or over admitted to study hospitals with a new stroke or with a nonpathological (ie non-metastatic) fractured neck of femur were eligible. New admissions were identified by contacting daily, usually by telephone, all the appropriate wards in each participating hospital to obtain the names of all eligible patients with a diagnosis of suspected stroke or fractured neck of femur. Five days after admission was chosen as the appropriate recruitment date to allow confirmation of diagnosis and for most patients to start to recover from the immediate trauma of both the event and admission to hospital. Patients were excluded if they died or were discharged before the admission interviews were due or the event had occurred while an inpatient. Patients who were too ill, as perceived by ward staff, at the time of the admission interview for their relatives to be contacted for consent were also excluded as it would have been ethically unacceptable to recruit dying patients. Patients who had a second admission with a study condition were not included a second time.

\section{PATIENT CONSENT}

Whenever possible, written consent was obtained from the patient themselves. If the. patient was unable to respond principally because of memory or communication problems, consent to include them in the study was obtained from the next of kin and admission interviews were not conducted with the patient themselves. Consent was sought from next of kin because excluding those most affected by the event initially would have led to a biased sample at discharge. 
Table 3 Difference between locations in recruitment

\begin{tabular}{|c|c|c|c|c|c|c|c|}
\hline & \multicolumn{7}{|c|}{ Location (\%) } \\
\hline & 1 & 2 & 3 & 4 & 5 & 6 & All \\
\hline Stroke & $n=161$ & $\mathrm{n}=191$ & $\mathrm{n}=131$ & $\mathrm{n}=132$ & $\mathrm{n}=183$ & $\mathrm{n}=93$ & $\mathrm{n}=891$ \\
\hline \multicolumn{8}{|l|}{ Not recruited: } \\
\hline Refused & 11 & 17 & 10 & 24 & 8 & 10 & 13 \\
\hline Consent not obtained & 6 & 8 & 3 & 4 & 22 & 11 & 10 \\
\hline Recruited & 83 & 74 & 87 & 72 & 70 & 79 & 77 \\
\hline Fractured neck of femur & $\mathrm{n}=203$ & $\mathrm{n}=265$ & $n=166$ & $\mathrm{n}=173$ & $\mathrm{n}=268$ & $\mathrm{n}=145$ & $\mathrm{n}=1220$ \\
\hline \multicolumn{8}{|l|}{ Not recruited: } \\
\hline Refused & 10 & 11 & 8 & 27 & 6 & 13 & 12 \\
\hline Consent not obtained & 6 & 13 & 4 & 3 & 10 & 5 & 7 \\
\hline Recruited & 84 & 76 & 88 & 70 & 84 & 82 & 81 \\
\hline
\end{tabular}

Using a $\chi^{2}$ test there is an association between location and whether the subject was recruited to the study for stroke $(p<0.01)$ or fractured neck of femur $(p<0.001)$.

\section{PARTICIPANTS}

Data were collected from patients (subjects), significant others, and nursing staff caring for subjects. The significant other was the relative, friend, or member of staff (if the patient lived in a residential or nursing home) who knew most about the patient before admission. Significant others were identified at admission in the subject or nurse interview. Data were collected where possible from a significant other for each subject, not only to supplement data from subjects when they were unable to complete an interview because they were acutely ill but also as a data source in their own right to provide information on those aspects of a hospital stay and discharge that affect a significant other. If at any time a subject or a significant other on their behalf refused to take further part in the study they were not contacted again.

\section{DATA COLLECTION}

Interviews took place after admission, after discharge and six months after admission (table 1). The aim of admission interviews was to obtain data about the circumstances surrounding the patient's admission, their status and living conditions before the stroke or fracture, present health status, and expectations for recovery and discharge. The nursing staff interview included a measure of the subject's functional ability (measured by the Barthel ADL index ${ }^{17}$ ) and of the level of confusion (measured by the confusion subscale of the modified Crichton Royal behavioural scale ${ }^{18}$ ). Discharge interviews with a hospital nurse took place as close to the time of discharge as possible to obtain details of the subject's hospitalisation and discharge. Interviews 10 days after discharge ascertained details about the subject's accommodation, service use, ability to perform everyday tasks, and details and perceptions of the discharge. Six month outcome interviews obtained information on the subject's living arrangements, service use, health status, functional abilities, and satisfaction. If a subject had been admitted to an institution after discharge and the significant other was a relative or friend, an additional outcome interview was conducted with a member of staff of the institution.

\section{FACILITATING RESPONSE}

Specially trained local lay people were employed as interviewers and were paid by the hour rather than per interview. This method of payment encouraged interviewers to allocate the time necessary to obtain interviews with frail, missing, or busy respondents. The interviewers were very carefully selected, trained, and managed. They underwent a standard five day training programme: three days spent at the research centre training in approaching and interviewing frail older peo-

Table 4 Admission characteristics of subjects who were discharged, for whom six month outcome data are or are not available

\begin{tabular}{|c|c|c|c|c|c|c|c|c|}
\hline & \multicolumn{3}{|l|}{ Stroke } & \multicolumn{3}{|c|}{ Fractured neck of femur } & \multicolumn{2}{|c|}{ Significance levels* } \\
\hline & $\begin{array}{l}\text { Responders } \\
(n=407)\end{array}$ & $\begin{array}{l}\text { Lost by drop-out } \\
(n=57)\end{array}$ & $\begin{array}{l}\text { Died } \\
(n=62)\end{array}$ & $\begin{array}{l}\text { Responders } \\
(n=602)\end{array}$ & $\begin{array}{l}\text { Lost by drop-out } \\
(n=144)\end{array}$ & $\begin{array}{l}\text { Died } \\
(n=113)\end{array}$ & Survival & Drop out \\
\hline \multicolumn{9}{|l|}{ Age $(y)$ : } \\
\hline Median & 76 & 77 & 82 & 82 & 84 & 86 & $S \mathrm{p}<0.0001$ & $S p=0.76$ \\
\hline \multirow{2}{*}{\multicolumn{9}{|c|}{ Gender (\%): }} \\
\hline & & & & & & & & \\
\hline Male & 45 & 49 & 37 & 14 & 15 & 17 & $S p=0.24$ & $S p=0.51$ \\
\hline \multirow{2}{*}{\multicolumn{9}{|c|}{ Marital status (\%)†: }} \\
\hline & & & & & & & & \\
\hline Married & 42 & 60 & 39 & 22 & 20 & 18 & $\mathrm{Sp}=0.42$ & $S p=0.01$ \\
\hline Single/widowed/divorced/separated & 58 & 40 & 61 & 77 & 80 & 82 & $\mathrm{~F} \mathrm{p}=0.37$ & $\mathrm{~F} p=0.57$ \\
\hline \multicolumn{9}{|l|}{ Accommodation $(\%) \dagger:$} \\
\hline Private household & 94 & 98 & 82 & 76 & 83 & 39 & $S p<0.001$ & $S p=0.16$ \\
\hline Institution & 6 & 2 & 18 & 24 & 17 & 61 & $\mathrm{Fp}<0.0001$ & $F p=0.07$ \\
\hline \multicolumn{9}{|l|}{ Functional ability (Barthel score) $\dagger$ : } \\
\hline Median & 8 & 10 & 4 & 9 & 10 & 4 & $S \mathrm{p}<0.0001$ & $S p=0.02$ \\
\hline Quartiles & $4-13$ & $5-17$ & $1-7$ & $5-13$ & $6-13$ & $2-7$ & $\mathrm{~F} \mathrm{p}<0.0001$ & $F p=0.76$ \\
\hline \multicolumn{9}{|l|}{ Confusion (\%): } \\
\hline None & 56 & 56 & 24 & 61 & 63 & 33 & & \\
\hline Mild & 15 & 14 & 21 & 10 & 10 & 11 & $S p<0.0001$ & $S p=0.90$ \\
\hline Moderate & 7 & 11 & 10 & 11 & 7 & 11 & $\mathrm{~F} p<0.0001$ & $F p=0.48$ \\
\hline Severe & 4 & 3 & 16 & 10 & 14 & 31 & & \\
\hline Not recorded & 18 & 16 & 29 & 8 & 6 & 14 & & \\
\hline \multicolumn{9}{|l|}{ Location (\%): } \\
\hline 1 & 21 & 25 & 8 & 18 & 15 & 18 & & \\
\hline 2 & 18 & 18 & 23 & 20 & 19 & 24 & & \\
\hline 3 & 17 & 15 & 21 & 15 & 19 & 12 & $S p=0.27$ & $S p=0.04$ \\
\hline 4 & 13 & 26 & 18 & 10 & 15 & 15 & $\mathrm{Fp}=0.52$ & $\mathrm{Fp}=0.14$ \\
\hline 5 & 19 & 14 & 19 & 24 & 25 & 19 & & \\
\hline 6 & 12 & 2 & 11 & 13 & 7 & 12 & & \\
\hline
\end{tabular}

* Significance levels are reported for subjects with stroke $(S)$ and fractured neck of femur $(F)$ using $\chi^{2}$ tests or Mann-Whitney $U$ tests with adjustment for ties as appropriate for survivors compared with non-survivers and drop outs compared with responders.

† Admission data was not available on marital status for 7 stroke and 9 fracture subjects, on accommodation for 4 and 8 , and on Barthel for 16 and 16 . 


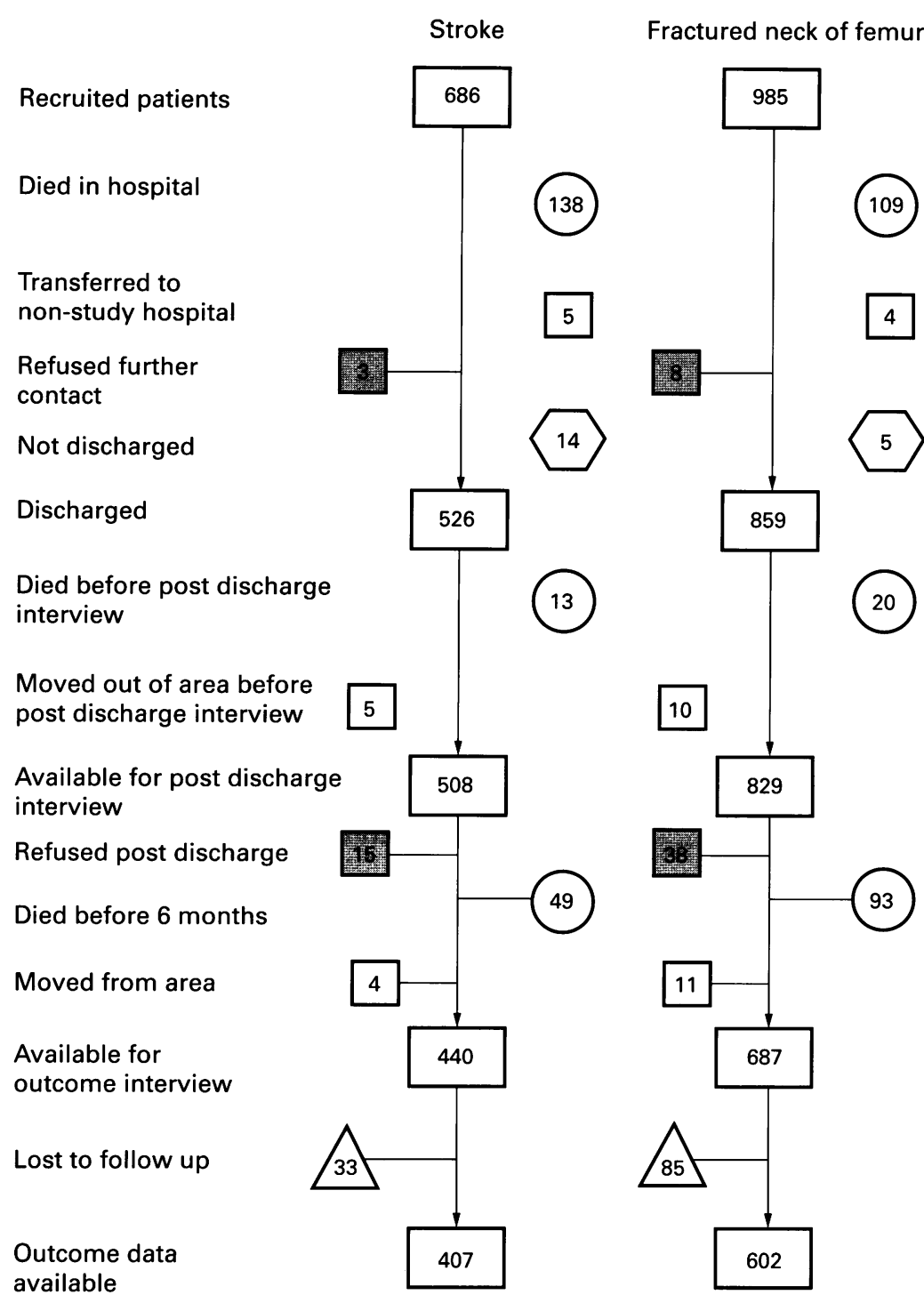

Figure 1 Audit trail of the study patients. sending three newsletters during the recruitment period. Patient and staff interest was maintained by sending Christmas cards to each subject if they had been discharged, and to each ward.

ANALYSIS

The data were analysed using SPSS to perform $\chi^{2}$ tests or Mann-Whitney U tests (with adjustment for tied values) as appropriate. Nonrecruitment bias was investigated within each diagnostic group with respect to gender, age, and location, which were the only variables available for all subjects referred to the study. Loss to follow up and interview response bias were investigated within each diagnostic group with respect to age, gender, marital status, accommodation before admission, functional ability, and confusion level as measured in the staff admission interview. Odds ratios (OR) and differences in medians (D) are reported together with their associated confidence intervals (CI).

\section{Results}

RECRUITMENT OF SUBJECTS

In total, 3105 patients were referred to the study: 1645 with an initial diagnosis of stroke and 1460 with a diagnosis of fractured neck of femur (table 2). Altogether $29 \%$ of notifications were not eligible for the study, mainly because they had died before interviews could be undertaken or because the diagnosis was confirmed to be other than a stroke or fractured neck of femur. Confirming eligibility was a particular problem for those initially identified as stroke patients where mortality was high in the early days after admission and diagnostic accuracy less certain. Of 891 patients with a stroke and 1220 patients with a fractured neck of femur who were eligible for the study, $21 \%$ were not recruited either because they refused or because they were too mentally or physically frail themselves to give informed consent and an appropriate next of kin was not traced in time to give consent.

days spent in practice under supervision. Ac tional training days and monitoring of performance continued throughout the study. Interviewers were responsible for following up each of their subjects, ensuring they knew which ward they were on, when they were going to be discharged and where to. In a longitudinal study it is important to maintain goodwill in the hospital and the local community. One way to do this is to reduce the likelihood of causing distress and embarrassment by trying to contact subjects who have died. Deaths were monitored when visiting wards and by scanning the local papers for death notices and lists of death registrations obtained from the health authorities. Letters of condolence were sent which assured significant others they would not be contacted again. A database of all respondents was used to prompt interviewers when interviews were due and to allow the project team to monitor progress. Throughout the study, face to face interviews were used in preference to postal questionnaires to maintain response and interest. Nursing staff were informed of study progress by

\section{NON-RECRUITMENT BIAS}

Recruited stroke patients had a median age of 78 years (quartiles: 72,84 ), while nonrecruited patients were older and had a median age of 80 years (quartiles: 73, 84) (D 2; CI 0 , 3 ). There was no difference in the age of recruited and non-recruited fractured neck of femur patients (median age 83 years, quartiles: 77,88 ). Recruitment of eligible stroke patients was significantly higher in location 3 and lower in location $5(\mathrm{p}<0.01)$ (table 3$)$, while recruitment of fractured neck of femur patients was significantly higher in location 3 and lower in location $4(p<0.001)$. Fitting a log linear model confirmed the location effect was consistent across diagnoses There were no differences between those not recruited and those recruited with respect to gender.

\section{ATTRITION}

Figure 1 shows an audit trail of subjects through the study. The aim of the study required a sample of discharged patients. Of 
Table 5 Percentage of each type of interview obtained for subjects who were discharged and available at each time point

\begin{tabular}{lll}
\hline & Stroke (\%) & $\begin{array}{l}\text { Fractured neck of } \\
\text { femur (\%) }\end{array}$ \\
\hline Admission interviews: & $\mathrm{n}=526$ & $\mathrm{n}=859$ \\
Staff & 100 & 100 \\
Patient & 69 & 73 \\
Significant other & 90 & 85 \\
Neither patient nor significant other & 2 & 2 \\
Discharge interviews: & 95 & 96 \\
Staff & $\mathrm{n}=508$ & $\mathrm{n}=829$ \\
Post discharge interviews: & 62 & 60 \\
Patient & 84 & 76 \\
Significant other & 9 & 12 \\
Neither patient nor significant other & $\mathrm{n}=440$ & $\mathrm{n}=687$ \\
Outcome interviews: & 71 & 65 \\
Patient & 38 & 23 \\
Informal significant other & 27 & 31 \\
Formal significant othert & 8 & 12 \\
None & & \\
\hline
\end{tabular}

* Relative or friend. $\uparrow$ Staff in institution.

subjects recruited to the study over $80 \%$ were followed to discharge. Death was the main reason for loss before this point. Only 11 subjects refused further involvement. Outcome data were achieved for $77 \%$ of discharged subjects with stroke and $70 \%$ of discharged subjects with fracture. Attrition after discharge was mainly due to differential survival: mortality accounting for $12 \%$ of stroke and $13 \%$ of fracture subjects. Of the 458 surviving stroke patients and 733 fracture patients, outcome data were obtained for $89 \%$ and $82 \%$ respectively. Compared with those surviving, subjects who had died since discharge were older (stroke $\mathrm{D}=5$; CI 3, 5; fracture $\mathrm{D}=3$; CI 3, 5), more likely to be living in an institution before admission to hospital (stroke OR 3.5; CI 1.6, 7.4; fracture OR 5.5 ; CI $3.6,8.3$ ), to have poorer functional ability (stroke $\mathrm{D}=4$; CI 2,5 : fracture $\mathrm{D}=4 ; \mathrm{CI} 3,5$ ), and to have severe confusion at admission (severe/none: stroke OR 8.6; CI 3.4, 21.6; fracture OR 5.2; CI 3.1, 8.8) (table 4 ). The only differences between those for whom six month outcome data were obtained and those who had dropped out of the study were among subjects with stroke: data were less likely to be obtained for those with higher functional ability at admission $(D=2 ; C I$ 0,4 ), those who were married (OR 2.0; CI 1.1, 3.5) and those from location 4 (OR 2.4; CI 1.2, 4.6).

INTERVIEW RESPONSE RATE

Table 5 shows the proportion of each interview type that was obtained for discharged subjects at each time point according to the number of subjects still alive and resident locally who had not previously refused further participation. At admission and discharge the study aimed to interview both subjects and significant others. At these times fewer subjects than significant others responded. At outcome the aim was to supplement subject data only if necessary.

RESPONSE AT ADMISSION

Essential baseline data were collected in nursing staff interviews and therefore these were obtained for all subjects. For each diagnosis non-responding subjects were older (stroke $\mathrm{D}=3$; $\mathrm{CI} 1,4$; fracture $\mathrm{D}=3$; $\mathrm{CI} 2,4$ ), more likely to live in an institution (stroke OR
5.5; CI 2.7, 11.2; fracture OR 12.9; CI 9.0, 18.4), had much lower functional ability (stroke $\mathrm{D}=5$; CI 4, 6; fracture $\mathrm{D}=6$; CI 6,7 ) and exhibited higher confusion levels (severe/ none: stroke OR 28.5; CI 11.5, 71.0; fracture OR 147.8; CI 74.3, 294.2) (table 6). Interviews were more likely to be obtained with significant others of subjects who were less able, particularly when the patient had fractured their hip (functional ability $\mathrm{D}=2$; CI 1,3 ; living in institution OR 3.1; CI 1.8, 5.3; severe confusion OR 3.4; CI 1.6, 7.3) (table 7). Interviews were less likely to be achieved with significant others in location 5 (OR 1.8; CI 1.2, 2.6). Overall some preadmission data (from subject or significant other interviews) were obtained for $98 \%$ of subjects.

\section{RESPONSE AT DISCHARGE}

Interviews were more likely to be obtained with patients who were younger (stroke $\mathrm{D}=3 ; \mathrm{CI} 2$, 4 ; fracture $\mathrm{D}=3$; CI 2,4 ), who lived in a private household before admission (stroke OR 3.8; CI 1.8, 7.9; fracture OR 5.9; CI 4.2, 8.2), who had higher functional ability at admission (stroke $\mathrm{D}=3$; CI 2, 4; fracture $\mathrm{D}=5$; CI 4, 5) and less confusion at admission (none/severe: stroke OR 13.0; CI 5.0, 33.9; fracture OR 22.3; CI $12.4,40.1)$. In addition, subjects with stroke in location 4 were less likely to respond (OR 1.9; CI 1.2, 3.2). Significant others were more likely to be interviewed if the subject had lower functional ability at admission (stroke $\mathrm{D}=2 ; \mathrm{CI} 1,4$; fracture $\mathrm{D}=2 ; \mathrm{CI} 1,3$ ) or were more confused at admission (severe/none: stroke OR 3.2; CI $0.7,13.8$; fracture OR 2.5; CI 1.4, 4.3). Interviews were also more likely to be conducted with significant others for subjects with fractured neck of femur who had lived in a nursing or residential home before admission (OR 3.1; CI 2.0, 4.9).

\section{RESPONSE AT OUTCOME}

Outcome interviews were conducted with the subject alone, if possible, but where appropriate supplemented with data from the informal significant other. If the subject was unable to respond the interview took place with the significant other. If the subject was residing in an institution at six months an interview was also conducted with a member of staff. An interview was more likely to be achieved with a subject or their informal significant other if the subject was younger (stroke $D=4 ; C I 2,6$; fracture $\mathrm{D}=3$; $\mathrm{CI} 2,4$ ), was admitted to hospital from a private household (stroke OR 6.9; CI 3.0, 15.6; fracture OR 8.9; CI 6.0, 13.3), had a higher functional ability at admission (stroke $\mathrm{D}=3$; CI 1,4 ; fracture $\mathrm{D}=4$; CI 3,5 ) and exhibited less confusion at admission (none/severe: stroke OR 12.6, CI 4.6, 34.2; fracture OR 16.8; CI 9.4, 29.9). Subjects for whom a member of staff was interviewed were older (stroke $\mathrm{D}=5$; CI 3, 6; fracture $\mathrm{D}=4$; CI 3, 5), more likely to be female (stroke OR 2.3; CI 1.5, 3.6; fracture OR 1.7; CI 1.0, 2.8), less likely to be married(stroke OR 0.2 ; CI 0.1 , 0.4 ; fracture OR 0.3 ; CI $0.2,0.4$ ), more likely to have been admitted from an institution (stroke OR 39.8; CI 9.2, 171.4; fracture OR 
33.7; CI 20.6, 55.2), had lower functional ability at admission (stroke $\mathrm{D}=6$; CI 5,7 ; fracture $\mathrm{D}=5$; CI 4,5 ), were more likely to be severely confused at admission (severe/none: stroke OR 12.5; CI 4.5, 34.9; fracture OR 18.2; CI 10.1, 32.5). These differences reflect

Table 6 Charactersitics of subjects who were discharged and for whom a patient admission interview had been obtained

\begin{tabular}{|c|c|c|c|c|c|}
\hline & \multicolumn{2}{|l|}{ Stroke } & \multicolumn{3}{|c|}{ Fractured neck of femur } \\
\hline & $\begin{array}{l}\text { Responders } \\
(n=361)\end{array}$ & $\begin{array}{l}\text { Lost by drop-out } \\
(n=165)\end{array}$ & $\begin{array}{l}\text { Responders } \\
(n=625)\end{array}$ & $\begin{array}{l}\text { Lost by drop-out } \\
(n=234)\end{array}$ & $\begin{array}{l}\text { Significance } \\
\text { levels }\end{array}$ \\
\hline \multicolumn{6}{|l|}{ Age $(y)$ : } \\
\hline Median & 76 & 79 & 82 & 85 & $S \mathrm{p}<0.0001$ \\
\hline Quartiles & $71-82$ & $73-85$ & $76-86$ & $80-89$ & $\mathrm{~F} \mathrm{p}<0.0001$ \\
\hline \multicolumn{6}{|l|}{ Gender (\%): } \\
\hline Male & 46 & 40 & 16 & 13 & $S p=0.20$ \\
\hline Female & 54 & 60 & 84 & 87 & $\mathrm{~F} p=0.29$ \\
\hline \multicolumn{6}{|l|}{ Marital status (\%)†: } \\
\hline Married & 45 & 43 & 23 & 16 & $S p=0.70$ \\
\hline Single/widowed/divorced/separated & 55 & 57 & 77 & 84 & $\mathrm{~F} \mathrm{p}=0.03$ \\
\hline \multicolumn{6}{|l|}{ Accommodation (\%) $\ddagger$ : } \\
\hline Private household & 97 & 84 & 87 & 34 & $S \mathrm{p}<0.0001$ \\
\hline Institution & 3 & 16 & 13 & 66 & $\mathrm{~F} p<0.0001$ \\
\hline \multicolumn{6}{|l|}{ Functional ability (Barthel score) \$: } \\
\hline Median & 9 & 4 & 10 & 3 & $S \mathrm{p}<0.0001$ \\
\hline Quartiles & $6-15$ & $1-7$ & $7-13$ & $1-6$ & $F p<0.0001$ \\
\hline \multicolumn{6}{|l|}{ Confusion $(\%)$ : } \\
\hline None & 69 & 15 & 77 & 8 & \\
\hline Mild & 16 & 13 & 9 & 11 & $S p<0.0001$ \\
\hline Moderate & 5 & 15 & 7 & 19 & $\mathrm{~F} p<0.0001$ \\
\hline Severe & 2 & 13 & 3 & 43 & \\
\hline Not recorded & 8 & 44 & 4 & 19 & \\
\hline \multicolumn{6}{|l|}{ Location (\%): } \\
\hline 1 & 20 & 18 & 16 & 21 & \\
\hline 2 & 19 & 19 & 19 & 24 & \\
\hline 3 & 15 & 22 & 16 & 13 & $S p=0.14$ \\
\hline 4 & 14 & 18 & 13 & 9 & $\mathrm{~F} \mathrm{p}=0.09$ \\
\hline 5 & 20 & 15 & 24 & 20 & \\
\hline 6 & 12 & 8 & 12 & 13 & \\
\hline
\end{tabular}

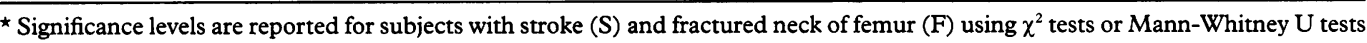
with adjustment for ties as appropriate.

† Marital status was not recorded for 7 stroke or 9 fracture subjects.

† Accomodation was not recorded for 4 stroke or 8 fracture subjects.

$\S$ Barthel was not recorded for 16 stroke or 16 fracture subjects.

Table 7 Charactersitics of subjects who were discharged and for whom a significant other admission interview had or had not been obtained

\begin{tabular}{|c|c|c|c|c|c|}
\hline & \multicolumn{2}{|l|}{ Stroke } & \multicolumn{3}{|c|}{ Fractured neck of femur } \\
\hline & $\begin{array}{l}\text { Responders } \\
(n=473)\end{array}$ & $\begin{array}{l}\text { Lost by drop-out } \\
(n=53)\end{array}$ & $\begin{array}{l}\text { Responders } \\
(n=727)\end{array}$ & $\begin{array}{l}\text { Lost by drop-out } \\
(n=132)\end{array}$ & $\begin{array}{l}\text { Significance } \\
\text { levels }\end{array}$ \\
\hline \multicolumn{6}{|l|}{ Age (y): } \\
\hline Median & 77 & 76 & 83 & 80 & $S p=0.02$ \\
\hline Quartiles & $72-83$ & $68-75$ & $77-87$ & $74-84$ & $\mathrm{~F} \mathrm{p}<0.001$ \\
\hline \multicolumn{6}{|l|}{ Gender (\%): } \\
\hline Male & 44 & 47 & 14 & 20 & $\mathrm{~S} p=0.64$ \\
\hline Female & 56 & 53 & 86 & 80 & $F p=0.05$ \\
\hline \multicolumn{6}{|l|}{ Marital status (\%)t: } \\
\hline Married & 44 & 45 & 21 & 24 & $S p=0.83$ \\
\hline Single/widowed/divorced/separated & 56 & 55 & 79 & 76 & $\mathrm{~F} p=0.41$ \\
\hline \multicolumn{6}{|l|}{ Accommodation (\%) $\ddagger$ : } \\
\hline Private household & 92 & 98 & 70 & 88 & $\mathrm{~S} p=0.11$ \\
\hline Institution & 8 & 2 & 30 & 12 & $\mathrm{~F} \mathrm{p}<0.001$ \\
\hline \multicolumn{6}{|l|}{ Functional ability (Barthel score) §: } \\
\hline Median & 7 & 8 & 8 & 11 & $S_{p}=0.40$ \\
\hline Quartiles & $4-12$ & $3-14$ & $5-12$ & $7-15$ & $\mathrm{~F} \mathrm{p}<0.0001$ \\
\hline \multicolumn{6}{|l|}{ Confusion (\%): } \\
\hline None & 51 & 58 & 55 & 75 & \\
\hline Mild & 15 & 13 & 10 & 8 & $S p=0.66$ \\
\hline Moderate & 8 & 4 & 11 & 5 & $\mathrm{~F} p<0.001$ \\
\hline Severe & 6 & 8 & 15 & 6 & \\
\hline Not recorded & 20 & 17 & 9 & 6 & \\
\hline \multicolumn{6}{|l|}{ Location (\%): } \\
\hline 1 & 19 & 26 & 18 & 14 & \\
\hline 2 & 19 & 11 & 21 & 15 & \\
\hline 3 & 19 & 6 & 15 & 16 & $S p=0.01$ \\
\hline 4 & 15 & 17 & 11 & 16 & $\mathrm{~F} \mathrm{p}<0.001$ \\
\hline 5 & 17 & 32 & 21 & 35 & \\
\hline 6 & 11 & 8 & 14 & 4 & \\
\hline
\end{tabular}

« Significance levels are reported for subjects with stroke (S) and fractured neck of femur $(F)$ using $\chi^{2}$ tests or Mann-Whitney U tests with adjustment for ties as appropriate.

Tarital status was not recorded for 7 stroke or 9 fracture subjects.

$\ddagger$ Accomodation was not recorded for 4 stroke or 8 fracture subjects.

$\S$ Barthel was not recorded for 16 stroke or 16 fracture subjects.

the characteristics of subjects in institutions as with those living in private houses. It is not possible to undertake these within residence type, as place of residence is not available for those who were not interviewed. 


\section{Discussion}

The method of identifying subjects early in their admission enabled complete enumeration of the target sample, although the drawback was the high number of ineligible subjects. This study was highly successful in recruiting subjects. The difference in recruitment between locations was mainly due to differences in the degree of success that interviewers had in identifying and gaining consent from significant others of subjects who were unable to give consent. This was a particular problem in location 5, a retirement area where subjects were less likely to have relatives living in the area. This was also seen in the lower rate of significant other interviews obtained at admission in this area. In location 4 the refusal rate was double that of the other locations. This particular hospital had problems with bed shortages and changes in organisational structure which resulted in subjects undergoing more ward moves, often to wards specialising in the care of other conditions. This might have affected subjects' willingness to take part in the study. Fewer interviews were obtained with stroke subjects in location 4 at discharge, although it is not clear whether this is related to the problems in the hospital or to other characteristics of the population.

It may be that a slightly higher response rate could have been achieved if interviewers had been members of staff wearing identifiable uniforms rather than lay interviewers. However, the research team felt that respondents would be more likely to give unbiased views of the processes of hospital care to people who were not seen as part of the organisation. The training programme and monitoring of performance of interviewers were an essential feature of the successful response rates. Evaluations have been conducted of different methods of conducting surveys, by mail, telephone, or face to face, ${ }^{1920}$ and of the effect of race or gender of interviewer for sensitive studies. ${ }^{2122}$ However, there is a dearth of experiments reported in the literature confirming the effects of utilising different techniques for improving the response rates and reducing attrition in interview surveys.

A high mortality rate in the study population was expected with subsequent loss to the discharge population. However, the study was also successful in following discharged patients up to outcome. Although the attrition rate appeared high at $23 \%$ for subjects with stroke and $30 \%$ for subjects with fractured neck of femur, most of this was due to differential survival rather than selective drop out. As expected those that died were frailer at admission than those that survived. Excluding loss due to death, outcome data were obtained for nearly $90 \%$ of subjects with stroke and over $80 \%$ of subjects with fractured neck of femur. The response rates to individual interviews were very high, particularly considering the extreme frailty of some of the subjects at admission, but also indicate the high proportion of initial data that would have been lost if interviews had not been conducted with significant others as well as subjects. Interviews with significant others were more likely to be obtained for frailer subjects. This may be because subjects who were less active before admission were more likely to have a close support network and were able to identify a significant other. Significant other interviews were particularly useful for information about subjects who were not interviewed. Among these subjects there were no differences between those for whom a significant other did respond and those for whom there was no significant other interview.

The time and effort put into maintaining contact with this extremely frail group of older people and their significant others was rewarded by the high response rates achieved and the low amount of attrition due to refusal. The very high response rates achieved with busy nursing staff are a sign not only of the success of the study protocol but also of the dedication of interviewers and of the commitment and interest of nursing staff. The methods used in this study to reduce attrition such as sending Christmas cards and newsletters should be formally evaluated. However, the benefit of high response was obtained at a higher cost of paying interviewers by the hour rather than by the interview and the effort of identifying a large number of people who were subsequently ineligible. This study indicates that it is essential to supplement data from older frail subjects by data from their significant others if the most frail are not to be totally disenfranchised. Further investigation is needed of the differences and similarities between responses from subjects and their significant others where both were interviewed.

This study was commissioned and funded by the Department of Health, however the views expressed remain the views of th authors. The project team would like to thank the hospital, community health and social service staff in the six study locations and all the patients and their families. Without their support and encouragement the study would not have been possible. The team would also like to thank the interviewers, coders and project secretaries for their diligence and support.

1 Moser CA, Kalton G. Survey methods in social investigation. 2nd ed. London: Heinemann, 1971.

2 Brenner $\mathrm{H}$. Alternative approaches for estimating prevalence in epidemiologic surveys with two waves of repsondents. Am $\mathcal{F}$ Epidemiol 1995;142(11):1236-45.

3 Norris FH. Characteristics of older nonrespondents over Norris FH. Characteristics of older nonrespondents over
five waves of a panel study. $\mathcal{F}$ Gerontol $1985 ; 40(5): 627-36$. 4 Vestbo J, Rasmussen FV. Baseline characteristics are not sufficient indicators of non-response bias in follow up studies. F Epidemiol Community Health 1992;46:617-9.

5 Melton LJ, Dyck PJ, Karnes KL, O'Brien PC, Service FJ Non-response bias in studies of diabetic complications The Rochester diabetic neuropathy study. $\mathcal{f}$ Clin Epidemio 1993;46(4):341-8.

6 Mittelmark MB, Psaty BM, Rautaharjum PM, et al. Prevalence of cardiovascular diseases among older adults. Am $\mathcal{F}$ Epidemiol 1993;137(3):311-7.

7 Herzog AR, Rodgers WL. Age and response rates to interview sample surveys. $\mathcal{f}$ Gerontol $1988 ; 43(6): S 200-5$.

8 Kelsey JL, O'Brien LA, Grisso JA, Hoffman S. Issues in carrying out epidemiologic research in the elderly. Am f Epide-
miol 1989;130:857-66.

9 Sheikh K. Predicting risk among non-respondents in pheikh K. Predicting risk among non-respondents
prospective studies. Eur $\mathcal{f}$ Epidemiol 1986;2(1):39-43.

10 Sonne-Holm S, Sorensen TIA, Jensen G, Schnohr P. Influence of fatness, intelligence, education and sociodemographic factors on response rate in a health survey. $\mathcal{F}$ Epide miol Community Health 1989;43:369-74.

11 Rockwood K, Stolee P, Robertson D, Shillington ER. Response bias in a health status survey of elderly people. Age Ageing 1989;18:177-82.

12 Cottler LB, Zipp JF, Robins LN, Spitznagel EL. Difficultto-recruit repsondents and their effect on prevalence 
estimates in an epidemiologic survey. Am $\mathcal{F}$ Epidemiol 1987; 125(2):329-39.

13 Billig N, Ahmed SW, Kenmore P, Amaral D, Shakhashiri MZ. Assessment of depression and cognitive impairment after hip fracture. 7 Am Geriatr Soc 1986:34 (7):499-503. tudinal oral health survey of older adults. Community Dentistry and Oral Epidemiology 1995;23:297-302.

5 Bisgard KM, Folsom AR, Hong C, Sellers TA. Mortality and cancer rates in nonrespondents to a prospective study and cancer rates in nonrespondents to a prospective study of older women: 5 -year

16 Baltes PB. The Berlin aging study (BASE): overview and design. Ageing Society 1993;13:483-515.

17 Mahoney FI, Barthel DW. Functional evaluation: The Barthel index. Maryland State Med $\mathcal{f} 1965 ; 14: 61-65$.
18 Wilkin D, Thompson C. Booth $\mathrm{T}$, eds. Users' guide to dependency measures for elderly people. Sheffield: University of Sheffield, Joint Unit for Social Services Research; 1989.

19 Weinberger M, Nagle B, Hanlon JT, et al. Assessing healthrelated quality of life in elderly outpatients: telephone verrelated quality of life in elderly outpatients: telephone versus face-to

20 Herzog AR, Rodgers WL, Kulka RA. Interviewing older adults: a comparison of telephone and face-to-face modalities. Public Opinion Quarterly 1983;47:405-18.

21 Freeman J, Butler EW. Some sources of interviewer variance in surveys. Public Opinion Quarterly 1976;40:79-91.

22 Berk ML, Bernstein AB. Interviewer characteristics and performance on a complex health survey. Social Science Research 1988;17:239-51. 